\title{
Intraoperative transfusion and an increased preoperative C-reactive protein level are associated with higher mortality after off-pump coronary artery bypass grafting
}

\author{
Karam Nam, MD, ${ }^{\mathrm{a}}$ Yunseok Jeon, MD, PhD, ${ }^{\mathrm{a}}$ Tae Kyong Kim, MD, PhD, ${ }^{\mathrm{b}}$ Ki-Bong Kim, MD, PhD,
} Ho Young Hwang, $\mathrm{MD}, \mathrm{PhD},{ }^{\mathrm{c}}$ and Youn Joung Cho, $\mathrm{MD}^{\mathrm{a}}$

\section{ABSTRACT}

Objective: The effects of transfusion on clinical outcomes after cardiac surgery remain inconclusive. We hypothesized that the risk of postoperative cumulative long-term, all-cause mortality after transfusion in patients undergoing cardiac surgery would differ by individual inflammatory status reflected by C-reactive protein level; thus, we performed a retrospective study.

Methods: All patients who underwent isolated off-pump coronary artery bypass grafting between October 2004 and October 2015 were retrospectively included. Patients were divided into 4 categories according to whether the preoperative $\mathrm{C}$ reactive protein level was greater than or less than $1 \mathrm{mg} / \mathrm{dL}$ and whether red cells were transfused intraoperatively. The 4 categories were as follows: low C-reactive protein without transfusion; low C-reactive protein with transfusion; high C-reactive protein without transfusion; and high C-reactive protein with transfusion. A multivariable Cox regression was then performed. Sensitivity analysis in subgroup ( $<3$ units of red cells transfused) was also performed.

Results: A total of 1636 patients were analyzed. Of the 4 categories, patients in the high C-reactive protein with transfusion group were at significantly higher risk of mortality than the low C-reactive protein without transfusion (hazard ratio, $1.86 ; 95 \%$ confidence interval, 1.24-2.79) or with transfusion group (hazard ratio, $1.47 ; 95 \%$ confidence interval, 1.13-1.93). A sensitivity analysis of patients who received only 1 or 2 units of red cells showed similar results.

Conclusions: Intraoperative red blood cell transfusion in patients with increased C-reactive protein level was significantly related to the risk of mortality after off-pump coronary artery bypass grafting. ( $\mathrm{J}$ Thorac Cardiovasc Surg 2020;159:558-65)

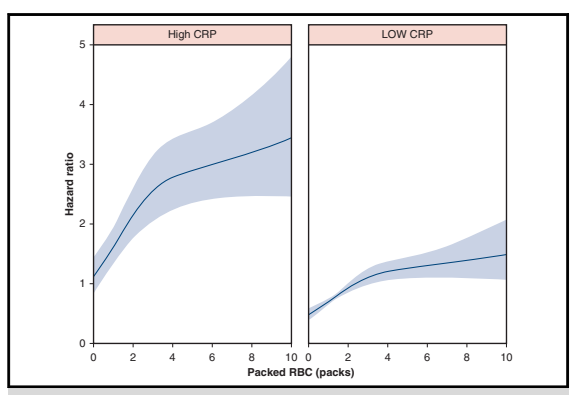

The HR for mortality according to the amount of RBCs and preoperative CRP level.

\section{Central Message}

The effect of intraoperative RBC transfusion on postoperative mortality after OPCAB can be affected by preoperative CRP level.

\section{Perspective}

Most studies have focused only on Hb levels in terms of transfusion triggers, yielding inconsistent results. In this study, intraoperative RBC transfusion in patients with elevated CRP level was related to significantly increased mortality after OPCAB. These results suggest that patients may need individualized transfusion triggers.

See Commentary on page 566.
The question of whether perioperative red blood cell (RBC) transfusion is hazardous is unanswered in the field of

\footnotetext{
From the ${ }^{\mathrm{a}}$ Department of Anesthesiology and Pain Medicine, Seoul National University Hospital, Seoul, Korea; ${ }^{\mathrm{b}}$ Department of Anesthesiology and Pain Medicine, SMG-SNU Boramae Medical Center, Seoul National University College of Medicine, Seoul, Korea; and ${ }^{\mathrm{c}}$ Division of Adult Cardiac Surgery, Department of Thoracic and Cardiovascular Surgery, Seoul National University Hospital, Seoul, Korea.

The study was approved by the Institutional Review Board of Seoul National University Hospital (No. 1803-097-930) on May 27, 2018.

Received for publication Sept 7, 2018; revisions received Jan 8, 2019; accepted for publication Jan 21, 2019; available ahead of print Feb 26, 2019.

Address for reprints: Youn Joung Cho, MD, Department of Anesthesiology and Pain Medicine, Seoul National University Hospital, 101 Daehak-ro, Jongno-gu, Seoul, Republic of Korea, 03080 (E-mail: mingming7@gmail.com).

0022-5223/\$36.00

Copyright (C) 2019 by The American Association for Thoracic Surgery

https://doi.org/10.1016/j.jtcvs.2019.01.078
}

cardiac surgery. Given the higher transfusion rate associated with such surgery compared with noncardiac surgery, ${ }^{1}$ an understanding of the risk of transfusion is of particular importance. However, the effects of transfusion on clinical outcomes after cardiac surgery remain inconclusive. Perioperative transfusion was reported to increase both shortterm $^{2-5}$ and long-term mortality ${ }^{5-8}$ after cardiac surgery. Transfusion of as few as 1 or 2 units of RBCs increased

- Scanning this QR code will take you to the article title page to access supplementary information. 


\section{Abbreviations and Acronyms \\ $\mathrm{CI}=$ confidence interval \\ $\mathrm{CRP}=\mathrm{C}$-reactive protein \\ $\mathrm{Hb}=$ hemoglobin \\ $\mathrm{HR}=$ hazard ratio \\ MI = myocardial infarction \\ $\mathrm{OPCAB}=$ off-pump coronary artery bypass grafting \\ $\mathrm{RBC}=$ red blood cell}

postoperative morbidity and mortality. ${ }^{2}$ In contrast, some studies found no association between transfusion and adverse outcomes after adjusting for perioperative risk factors. ${ }^{9-12}$

Hypoperfusion and ischemia-reperfusion injury trigger inflammation after cardiac surgery, particularly when cardiopulmonary bypass is used. ${ }^{13,14}$ Even off-pump procedures do not completely abolish (but may reduce) inflammation, ${ }^{15-17}$ which plays a major role in the pathogenesis of atherosclerosis, which in turn triggers vascular occlusive disease. ${ }^{18,19} \mathrm{C}$-reactive protein (CRP), a general marker of inflammation, both mediates and predicts the development of vascular occlusive diseases such as myocardial infarction (MI) and stroke, ${ }^{19-21}$ and predicts postoperative outcomes. ${ }^{22-25}$ Transfusion aggravates inflammation by stimulating the release of inflammatory cytokines, including interleukin-6, interleukin-8, and secretory phospholipase A2. ${ }^{26,27}$

Thus, the adverse effects of transfusion in patients undergoing cardiac surgery may be influenced by preexisting inflammation. To date, no study has explored a potential relationship between inflammation and transfusion, or the prognostic significance thereof. We hypothesized that patient outcomes would differ by individual inflammatory status reflected by preoperative CRP level; we performed a large, single-center, retrospective observational study to explore this possibility.

\section{MATERIALS AND METHODS Study Population}

The study was approved by the Institutional Review Board of Seoul National University Hospital (No. 1803-097-930); the requirement for written informed consent was waived because of the retrospective nature of the work. All consecutive patients who underwent isolated, off-pump coronary artery bypass grafting (OPCAB) in our tertiary teaching hospital from October 2004 to October 2015 were retrospectively included. Patients without preoperative CRP data obtained within 1 month before surgery were excluded.

\section{Perioperative Management and Transfusion Strategy}

Target-controlled infusions of propofol and remifentanil, volatile anesthetics, or continuous infusion of a mixture of midazolam and sufentanil was used for general anesthesia. Pulmonary arterial pressure, mixed venous oxygen saturation, cerebral oxygen sarutation, and transesophageal echocardiography were monitored intraoperatively. Intraoperative RBC transfusion was standardized. Intraoperative hemoglobin $(\mathrm{Hb})$ or hematocrit measurements were routinely performed every 1 to 2 hours after anesthesia induction, and additional tests were performed when necessary. RBCs were transfused to maintain the $\mathrm{Hb}$ level at greater than $9 \mathrm{~g} / \mathrm{dL}$ (hematocrit $>27 \%$ ). The $\mathrm{Hb}$ or hematocrit level was reassessed after completion of transfusion, and additional transfusion scheduled as necessary. Blood cell salvage was routinely performed.

All patients were transferred to the intensive care unit after surgery. Aspirin $100 \mathrm{mg} / \mathrm{d}$ was administered to all patients until the day of surgery and resumed as soon as possible after the surgery, mostly on the first postoperative day. Clopidogrel $75 \mathrm{mg} / \mathrm{d}$ was also added along with aspirin for 1 year after the surgery. Statin therapy was commenced if a patient had a low-density lipoprotein cholesterol level greater than $100 \mathrm{mg} / \mathrm{dL}$.

\section{Data Collection}

We collected the following data from electronic medical records: demographics, medication histories, comorbidities, preoperative laboratory data, preoperative ejection fraction, operative information including RBC transfusions, and postoperative morbidities (acute kidney injury defined using the creatinine criteria of the Kidney Disease: Improving Global Outcomes study, reintubation, and reoperation to control bleeding). We also recorded preoperative high-sensitivity CRP levels. Data on all-cause mortality were obtained from the database of the National Population Registry of the Korean National Statistical Office.

\section{Statistical Analysis}

The primary outcome was the risk of long-term all-cause mortality after OPCAB according to preoperative CRP level and intraoperative RBC transfusion. Secondary outcomes were 30-day, 90-day, 1-year, and 3-year mortality. Continuous variables are expressed as means (with standard deviations) or as medians (with interquartile ranges [IQRs]), as appropriate, and categoric variables are expressed as numbers (with \% values). Categoric variables were compared using the chi-square test or Fisher exact test, and continuous variables were compared using the analysis of variance or the Kruskal-Wallis test where appropriate. The 4 categories reflected whether the preoperative CRP level was greater than or less than $1 \mathrm{mg} / \mathrm{dL}$, based on previous studies, ${ }^{2,28}$ and whether RBCs were transfused intraoperatively. The categories were as follows: low CRP without transfusion, low CRP with transfusion, high CRP without transfusion, and high CRP with transfusion. To compare the risk of mortality, we performed Cox proportional hazards regression to calculate the hazard ratio (HR) of each group. Univariable analyses included demographic data, medical histories, preoperative medications, laboratory profiles, operative data, and postoperative morbidities, which are listed in Table 1. Three different multivariable Cox regressions were performed, permitting separate investigation of different types of the perioperative confounders. Model 1 was adjusted for preoperative variables including demographic data, medical history, preoperative medication, and preoperative clinical data. In Model 2, intraoperative and surgical data were adjusted for, as well as the preoperative variables. Postoperative comorbidities were added in Model 3.

Kaplan-Meier curves were then created, and survival was compared using the log-rank test. In addition, we performed the cubic spline analysis to see the change in the risk of mortality according to the amount of RBC transfusion, in which preoperative CRP level was adjusted for.

Sensitivity analysis was performed in a subgroup $(<3$ units of RBCs transfused) to evaluate whether the primary outcome was biased by including patients who received large amounts of RBCs, possibly because of excessive surgical bleeding. The multivariable Cox regression analysis was repeated in this subgroup.

All statistical analyses were performed with the aid of $\mathrm{R}$ software (ver. 3.4.3; R Development Core Team, Vienna, Austria). The cubic spline function curves were drawn using the rms package (ver. 5.1-2). 
TABLE 1. Baseline characteristics and perioperative data

\begin{tabular}{|c|c|c|c|c|c|}
\hline Variables & $\begin{array}{c}\text { Low CRP, no } \\
\text { RBC }(n=338)\end{array}$ & $\begin{array}{l}\text { Low CRP, yes } \\
\text { RBC }(n=952)\end{array}$ & $\begin{array}{l}\text { High CRP, no } \\
\text { RBC }(n=64)\end{array}$ & $\begin{array}{l}\text { High CRP, yes } \\
\text { RBC }(n=282)\end{array}$ & $\boldsymbol{P}$ \\
\hline Preoperative CRP (mg/dL) & $0.14(0.05-0.31)$ & $0.18(0.05-0.37)$ & $2.33(1.46-3.31)$ & $2.38(1.59-4.77)$ & \\
\hline Intraoperative RBC (units) & - & $3(2-4)$ & - & $3(2-4)$ & \\
\hline \multicolumn{6}{|l|}{ Demographic data } \\
\hline Age $(y)$ & $60.9(10.6)$ & $66.6(8.6)$ & $61.5(10.3)$ & $68.7(8.5)$ & $<.001$ \\
\hline Female & $92(27.2 \%)$ & $280(29.4 \%)$ & $20(31.3 \%)$ & $75(26.6 \%)$ & .706 \\
\hline BMI $\left(\mathrm{kg} / \mathrm{m}^{2}\right)$ & $25.5(3.1)$ & $24.5(3.0)$ & $24.5(2.9)$ & $23.3(3.0)$ & $<.001$ \\
\hline \multicolumn{6}{|l|}{ Medical history } \\
\hline Hypertension & $189(55.9 \%)$ & $646(67.9 \%)$ & $36(56.3 \%)$ & $199(70.6 \%)$ & $<.001$ \\
\hline Diabetes & $128(37.9 \%)$ & $461(48.4 \%)$ & $24(37.5 \%)$ & $156(55.3 \%)$ & $<.001$ \\
\hline Myocardial infarction & $26(7.7 \%)$ & $69(7.2 \%)$ & $13(20.3 \%)$ & $47(16.7 \%)$ & $<.001$ \\
\hline Congestive heart failure & $12(3.6 \%)$ & $46(4.8 \%)$ & $12(18.8 \%)$ & $43(15.2 \%)$ & $<.001$ \\
\hline Chronic liver disease & $40(11.8 \%)$ & $106(11.1 \%)$ & $9(14.1 \%)$ & $31(11.0 \%)$ & .891 \\
\hline Atrial fibrillation & $25(7.4 \%)$ & $72(7.6 \%)$ & $8(12.5 \%)$ & $28(9.9 \%)$ & .319 \\
\hline Cerebrovascular disease & $29(8.6 \%)$ & $124(13.0 \%)$ & $5(7.8 \%)$ & $42(14.9 \%)$ & .051 \\
\hline Previous PCI & $55(16.3 \%)$ & $125(13.1 \%)$ & $4(6.3 \%)$ & $31(11.0 \%)$ & .082 \\
\hline \multicolumn{6}{|l|}{ Preoperative medication } \\
\hline Aspirin & $241(71.3 \%)$ & $676(71.0 \%)$ & $21(32.8 \%)$ & $162(57.4 \%)$ & $<.001$ \\
\hline Clopidogrel & $79(23.4 \%)$ & $305(32.0 \%)$ & $17(26.6 \%)$ & $69(24.5 \%)$ & .006 \\
\hline ACEi/ARB & $119(35.2 \%)$ & $412(43.3 \%)$ & $13(20.3 \%)$ & $102(36.2 \%)$ & $<.001$ \\
\hline B-blocker & $82(24.3 \%)$ & $219(23.0 \%)$ & $8(12.5 \%)$ & $54(19.1 \%)$ & .102 \\
\hline Calcium channel blocker & $154(45.6 \%)$ & $461(48.4 \%)$ & $15(23.4 \%)$ & $123(43.6 \%)$ & .001 \\
\hline Diuretics & $30(8.9 \%)$ & $160(16.8 \%)$ & $10(15.6 \%)$ & $52(18.4 \%)$ & .002 \\
\hline Statin & $170(50.3 \%)$ & $522(54.8 \%)$ & $13(20.3 \%)$ & $110(39.0 \%)$ & $<.001$ \\
\hline \multicolumn{6}{|l|}{ Preoperative clinical data } \\
\hline LV ejection fraction $(\%)$ & $57(52-63)$ & $57(52-63)$ & $52(33-57)$ & $53(40-60)$ & $<.001$ \\
\hline LV ejection fraction $<35 \%$ & $24(7.1 \%)$ & $63(6.6 \%)$ & $17(26.6 \%)$ & $51(18.1 \%)$ & $<.001$ \\
\hline Serum creatinine $(\mathrm{mg} / \mathrm{dL})$ & $1.00(0.90-1.10)$ & $1.01(0.87-1.20)$ & $1.00(0.93-1.21)$ & $1.10(0.90-1.70)$ & .004 \\
\hline Hematocrit $(\%)$ & $34.4(4.6)$ & $34.8(4.7)$ & $33.6(4.9)$ & $33.7(4.5)$ & .004 \\
\hline IABP use within $72 \mathrm{~h}$ before surgery & $11(3.3 \%)$ & $66(6.9 \%)$ & $5(7.8 \%)$ & $27(9.6 \%)$ & .015 \\
\hline No. of diseased vessels & & & & & $<.001$ \\
\hline 1-vessel disease & $18(5.3 \%)$ & $17(1.8 \%)$ & $0(0.0 \%)$ & $8(2.8 \%)$ & \\
\hline 2-vessel disease & $49(14.5 \%)$ & $100(10.5 \%)$ & $15(23.4 \%)$ & $24(8.5 \%)$ & \\
\hline 3-vessel disease & $212(62.7 \%)$ & $666(70.0 \%)$ & $35(54.7 \%)$ & $203(72.0 \%)$ & \\
\hline Not specified & $59(17.5 \%)$ & $169(17.8 \%)$ & $14(21.9 \%)$ & $47(16.7 \%)$ & \\
\hline Left main disease & $33(9.8 \%)$ & $139(14.6 \%)$ & $5(7.8 \%)$ & $32(11.3 \%)$ & .057 \\
\hline \multicolumn{6}{|l|}{ Operative data } \\
\hline Re-do surgery & $11(3.3 \%)$ & $17(1.8 \%)$ & $0(0 \%)$ & $2(0.7 \%)$ & .073 \\
\hline Emergency surgery & $7(2.1 \%)$ & $40(4.2 \%)$ & $0(0 \%)$ & $8(2.8 \%)$ & .099 \\
\hline No. of distal anastomoses & $3(2-4)$ & $3(3-4)$ & $3(3-4)$ & $3(3-4)$ & .002 \\
\hline \multicolumn{6}{|l|}{ Coronary graft } \\
\hline Left internal thoracic artery & $320(94.7 \%)$ & $908(95.4 \%)$ & $62(96.9 \%)$ & $253(89.7 \%)$ & .003 \\
\hline Right internal thoracic artery & $36(10.7 \%)$ & $98(10.3 \%)$ & $8(12.5 \%)$ & $50(17.7 \%)$ & .007 \\
\hline Right gastroepiploic artery & $97(28.7 \%)$ & $282(29.6 \%)$ & $28(43.8 \%)$ & $79(28.0 \%)$ & .086 \\
\hline Saphenous vein & $193(57.1 \%)$ & $621(65.2 \%)$ & $35(54.75)$ & $182(64.5 \%)$ & .026 \\
\hline Intraoperative dobutamine use & $44(13.0 \%)$ & $193(20.3 \%)$ & $12(18.8 \%)$ & $92(32.6 \%)$ & $<.001$ \\
\hline Intraoperative dopamine use & $46(13.6 \%)$ & $124(13.0 \%)$ & $20(31.3 \%)$ & $54(19.1 \%)$ & $<.001$ \\
\hline Intraoperative epinephrine use & $5(1.5 \%)$ & $24(2.5 \%)$ & $5(7.8 \%)$ & $19(6.7 \%)$ & $<.001$ \\
\hline Intraoperative norepinephrine use & $176(52.1 \%)$ & $541(56.8 \%)$ & $32(50.0 \%)$ & $186(66.0 \%)$ & .003 \\
\hline Duration of surgery (min) & $357(310-400)$ & $375(335-415)$ & $360(316-400)$ & $376(340-425)$ & $<.001$ \\
\hline Intraoperative colloid (ml) & $1025(0-1700)$ & $1500(500-2000)$ & $0(0-1500)$ & $1150(150-1900)$ & $<.001$ \\
\hline Average minimum hematocrit $(\%)^{*}$ & $27.2(3.9)$ & $24.7(3.7)$ & $27.4(4.5)$ & $24.6(3.7)$ & $<.001$ \\
\hline
\end{tabular}


TABLE 1. Continued

\begin{tabular}{|c|c|c|c|c|c|}
\hline Variables & $\begin{array}{c}\text { Low CRP, no } \\
\text { RBC }(n=338)\end{array}$ & $\begin{array}{l}\text { Low CRP, yes } \\
\text { RBC }(n=952)\end{array}$ & $\begin{array}{l}\text { High CRP, no } \\
\text { RBC }(n=64)\end{array}$ & $\begin{array}{l}\text { High CRP, yes } \\
\text { RBC }(n=282)\end{array}$ & $P$ \\
\hline \multicolumn{6}{|l|}{ Postoperative morbidity } \\
\hline Postoperative AKI & $74(21.9 \%)$ & $320(33.6 \%)$ & $12(18.8 \%)$ & $91(32.3 \%)$ & $<.001$ \\
\hline Reintubation & $10(3.0 \%)$ & $60(6.3 \%)$ & $9(14.1 \%)$ & $47(16.7 \%)$ & $<.001$ \\
\hline Reoperation for bleeding control & $1(0.3 \%)$ & $28(2.9 \%)$ & $1(1.6 \%)$ & $16(5.7 \%)$ & .001 \\
\hline
\end{tabular}

Data are expressed as mean (SD), median (IQR), or number (\%). CRP, C-reactive protein; $R B C$, red blood cell; $B M I$, body mass index; $P C I$, percutaneous coronary intervention; $A C E i$, angiotensin-converting enzyme inhibitor; $A R B$, angiotensin receptor blocker; $L V$, left ventricle; $I A B P$, intra-aortic balloon pump; $A K I$, acute kidney injury. *The numbers of patients of each group were $292,852,47$, and 254 , respectively, because of missing values $(\mathrm{n}=191)$.

\section{RESULTS}

Of the 1663 patients who underwent isolated OPCAB, 27 were excluded because preoperative CRP data were lacking. The remaining 1636 patients were analyzed. Baseline characteristics and operative data are presented in Table 1. The median CRP levels were $0.14 \mathrm{mg} / \mathrm{dL}, 0.18 \mathrm{mg} / \mathrm{dL}$, $2.33 \mathrm{mg} / \mathrm{dL}$, and $2.38 \mathrm{mg} / \mathrm{dL}$ in the low CRP without transfusion, low CRP with transfusion, high CRP without transfusion, and high CRP with transfusion groups, respectively. The CRP levels were measured at a median (IQR) of 4 days (2-6) before surgery. The median (IQR) RBC transfusion level was 3 units (2-4) in patients who received transfusions.

The results of univariable and multivariable analyses are summarized in Table 2. The median (IQR) follow-up duration was 55 (23-89) months. The number (\%) of all-cause mortality was $341(20.8 \%)$ : low CRP without transfusion, $40(11.8 \%)$; low CRP with transfusion, $178(18.7 \%)$; high CRP without transfusion, $14(21.9 \%)$; and high CRP with transfusion, $109(39.5 \%)$. The combined variable was significantly associated with the risk of mortality after OPCAB in the Wald test $(P=.003$, Table 2$)$. Of the 4 categories, only patients in the high CRP with transfusion group were at significantly higher risk of mortality than the low CRP without transfusion group in all multivariable models (Model 3, HR, 1.86; 95\% confidence interval [CI], 1.24-2.79) (Table 2). In addition, the mortality risk was significantly greater in the high CRP with transfusion group than in the low CRP with transfusion group (HR, 1.47; 95\%
CI, 1.13-1.93) or the high CRP without transfusion group (HR, 2.00; 95\% CI, 1.09-3.65), although the risk of the low CRP with transfusion group was similar to that of the low CRP without transfusion group (HR, 1.26; 95\% CI, 0.87-1.83) (Table 2). There was no statistical difference between the low CRP with transfusion group and the high CRP without transfusion group (data not shown).

The Kaplan-Meier curves showed that cumulative survival after OPCAB differed significantly among the groups (Figure 1). Compared with the low CRP without transfusion group, the other 3 groups exhibited significantly poorer survival. In particular, the high CRP with transfusion group exhibited the poorest survival. The low CRP with transfusion and high CRP without transfusion groups survived to similar extents. The cubic spline function curves revealed that the HR associated with the same extent of transfusion was higher in patients with CRP levels greater than $1 \mathrm{mg} / \mathrm{dL}$ than less than $1 \mathrm{mg} / \mathrm{dL}$; the rate of $\mathrm{HR}$ increase was more pronounced in patients with higher CRP levels (Figure 2).

Sensitivity analysis of 964 patients who received less than 3 units of RBCs showed that the mortality risk remained significantly higher in the high CRP with transfusion group than in the low CRP with transfusion group (HR, 2.07; 95\% CI, 1.20-3.57); the mortalities of the other groups were not affected (Table 3 ).

Secondary outcomes are summarized in Table 4. Thirtyday, 90-day, 1-year, and 3-year mortality were higher in the

TABLE 2. Cox proportional hazard model for long-term mortality after off-pump coronary artery bypass grafting

\begin{tabular}{|c|c|c|c|c|c|c|c|c|c|}
\hline \multirow[b]{2}{*}{ Groups } & \multirow[b]{2}{*}{ Event n (\%) } & \multicolumn{2}{|c|}{ Univariable } & \multicolumn{2}{|c|}{ Multivariable 1* } & \multicolumn{2}{|c|}{ Multivariable 2 $\dagger$} & \multicolumn{2}{|c|}{ Multivariable 3} \\
\hline & & HR $(95 \%$ CI $)$ & $P$ & HR $(95 \%$ CI $)$ & $\boldsymbol{P}$ & HR $(95 \%$ CI $)$ & $\boldsymbol{P}$ & HR $(95 \%$ CI $)$ & $P$ \\
\hline Inflammation-transfusion & & & $<.001$ & & $<.001$ & & $<.001$ & & .003 \\
\hline Low CRP-no RBC & $40(11.8 \%)$ & Reference & & Reference & & Reference & & Reference & \\
\hline Low CRP-yes RBC & $178(18.7 \%)$ & $1.72(1.22-2.43)$ & & $1.20(0.84-1.72)$ & .316 & $1.31(0.91-1.89)$ & .153 & $1.26(0.87-1.83)$ & .215 \\
\hline High CRP-no RBC & $14(21.9 \%)$ & $1.83(0.99-3.37)$ & & $1.24(0.66-2.33)$ & .511 & $1.09(0.58-2.08)$ & .786 & $0.93(0.48-1.79)$ & .833 \\
\hline High CRP-yes RBC & $109(38.7 \%)$ & $4.32(3.00-6.23)$ & & $2.07(1.40-3.04)$ & $<.001$ & $2.09(1.40-3.13)$ & $<.001$ & $1.86(1.24-2.79)$ & .003 \\
\hline
\end{tabular}




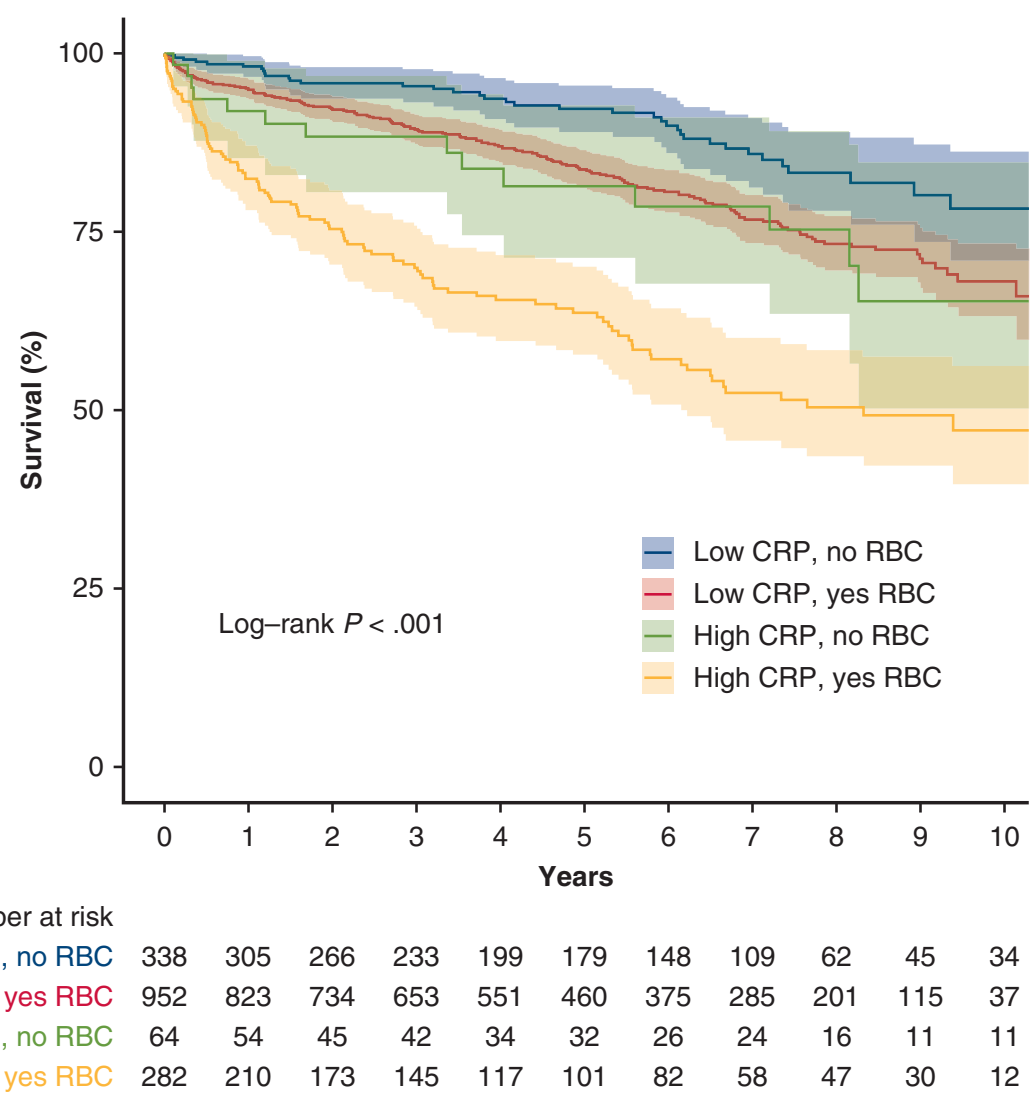

FIGURE 1. Kaplan-Meier survival curves according to inflammation-transfusion strata. The cumulative survival differed significantly among the strata. Compared with the low CRP without transfusion group, the high CRP with transfusion group showed poorer survival. $C R P$, C-reactive protein; $R B C$, red blood cell.

high CRP with transfusion group compared with the other groups (Table 4).

\section{DISCUSSION}

In this large retrospective study, we found that the effect of intraoperative RBC transfusion on postoperative mortality after OPCAB may be affected by preoperative CRP level (Video 1). The mortality of patients who received intraoperative RBC transfusions differed by their baseline CRP levels. Patients in the high CRP with transfusion group had a significantly higher risk of mortality than the low CRP without transfusion group or with transfusion group (1.9- and 1.5-fold higher risk, respectively). Similar results were observed in subgroup analysis including only patients receiving less than 3 units of RBCs.

Traditionally, many clinicians set the transfusion trigger higher ( $\mathrm{Hb}$ level $<9-10 \mathrm{~g} / \mathrm{dL}$ ) for patients undergoing cardiac surgery than noncardiac surgery, seeking to maintain adequate tissue perfusion. As the adverse effects of transfusion became more widely recognized, ${ }^{3,29,30}$ many studies have addressed transfusion strategies/triggers for patients undergoing cardiac surgery. However, most have focused only on $\mathrm{Hb}$ levels, yielding inconsistent results. Several observational studies reported that perioperative RBC transfusion negatively affected outcomes, ${ }^{2-8}$ but others advocated transfusion, observing that the harmful effects were not significant after adjusting for various clinical confounders. ${ }^{9-12}$ Even large, multicenter randomized trials have drawn different conclusions. ${ }^{31,32}$ The Transfusion Indication Threshold Reduction (TITRe2) trial favored a liberal transfusion threshold ( $\mathrm{Hb}$ level $<9 \mathrm{~g} / \mathrm{dL}$ ) over a restrictive threshold $(\mathrm{Hb}$ level $<7.5 \mathrm{~g} / \mathrm{dL}) .{ }^{31}$ In that study, all-cause mortality at 90 days was significantly higher in the restrictive group than in the liberal group $(4.2 \%$ vs $2.6 \%$ ), although this was a secondary outcome. Moreover, the restrictive threshold was not superior to the liberal threshold in terms of the primary outcome (a composite of serious wound infection, sepsis, MI, intestinal infarction, and acute kidney injury). ${ }^{31}$ The TITRe2 investigation raised uncertainty regarding whether transfusion should be restricted in patients undergoing cardiac surgery (who usually have marginal cardiovascular reserves and are thus at high risks of frequent transfusion). ${ }^{33,34}$ However, in the Transfusion Requirements in Cardiac Surgery (TRICS III) trial, a restrictive transfusion strategy was not inferior to a liberal strategy in terms of a composite outcome 


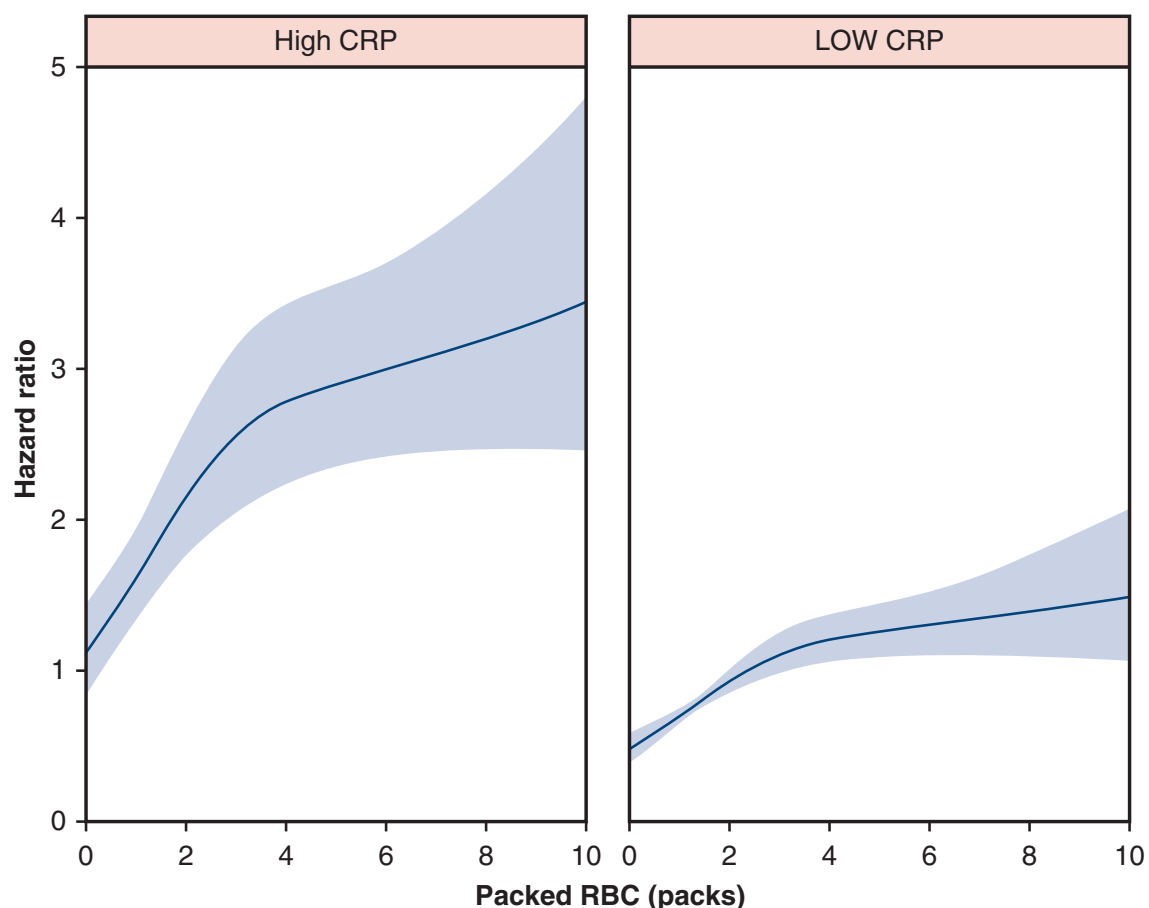

FIGURE 2. Cubic spline function curves for HR according to the amount of transfusion in patients with high and low CRP level, respectively. The HR for mortality was higher and increased more rapidly in patients with CRP levels greater than $1 \mathrm{mg} / \mathrm{dL}$ than less than $1 \mathrm{mg} / \mathrm{dL}$. Blue bands refer to $95 \%$ CI. CRP, C-reactive protein; $R B C$, red blood cell.

consisting of death, MI, stroke, and renal failure (11.4\% vs $12.5 \%) .^{32}$ The TRICS investigators favored the restrictive strategy; the risk of the composite outcome was lower compared with that of the liberal strategy in an elderly subgroup. $^{32}$

The adverse effects of RBC transfusion may be multifactorial. $^{29,30}$ Leucocyte microchimerism after RBC transfusion is immunomodulatory, increasing the risk of infection, organ failure, and inflammation. ${ }^{35,36}$ However,

TABLE 3. Subgroup analysis on patients with less than 3 units of red blood cell transfused

\begin{tabular}{cclcc}
\hline Groups & $\begin{array}{c}\text { Event, } \\
\mathbf{n}(\%)\end{array}$ & $\begin{array}{c}\text { Adjusted } \\
\text { HR}^{*}\end{array}$ & $\mathbf{9 5 \%} \mathbf{C I}$ & $\boldsymbol{P}$ \\
\hline $\begin{array}{c}\text { Inflammation-transfusion } \\
\text { Low CRP-no RBC } \\
(\mathrm{n}=338)\end{array}$ & $40(11.8 \%)$ & Reference & & \\
$\begin{array}{c}\text { Low CRP-yes RBC } \\
(\mathrm{n}=449)\end{array}$ & $57(12.7 \%)$ & 1.28 & $0.82-2.00$ & .278 \\
$\begin{array}{c}\text { High CRP-no RBC } \\
(\mathrm{n}=64)\end{array}$ & $14(21.9 \%)$ & 0.92 & $0.44-1.89$ & .813 \\
$\begin{array}{c}\text { High CRP-yes RBC } \\
(\mathrm{n}=113)\end{array}$ & $31(27.4 \%)$ & 2.07 & $1.20-3.57$ & .009 \\
\hline
\end{tabular}

The adjusted HR (95\% CI) of High CRP-yes RBC was 1.61 (0.98-2.66), $P=.060$ and 2.26 (1.06-4.83), $P=.036$, compared with Low CRP-yes RBC and High CRP-no $\mathrm{RBC}$, respectively. $H R$, Hazard ratio; $C I$, confidence interval; $C R P$, C-reactive protein; $R B C$, red blood cell. *Adjusted for all variables of Multivariable model 3 in Table 2 . leucocyte-depleted RBC transfusion did not reduce microchimerism. ${ }^{37}$ Patients with coronary artery disease, particularly those undergoing coronary artery bypass grafting, may be more susceptible to the adverse effects of RBC transfu$\operatorname{sion}^{4,6}$; thrombosis, intimal hyperplasia, or atherosclerosis may be aggravated by leucocyte-mediated inflammation, triggering graft occlusion or failure after revascularization. $^{38}$ The pivotal role played by inflammation is emphasized by the fact that an elevated, perioperative CRP level was associated with increased risks of long-term mortality, length of hospital stay, ${ }^{24}$ and major adverse cardiovascular and cerebral events after coronary artery bypass grafting. ${ }^{22}$ Thus, we consider that the effect of transfusion on mortality after OPCAB is potentiated by preoperative inflammation. To the best of our knowledge, this is the first study to explore the effects of the relationship between inflammation and transfusion on patient outcomes. As mentioned earlier, previous studies focused only on $\mathrm{Hb}$ levels. Given our results and those of a previous study on anemia/transfusion interactions, ${ }^{38}$ the present approach may be inappropriate for some patients. Unknown interactions may be in play between transfusion and other clinical variables affecting patient outcomes. Further studies are required.

We dichotomized preoperative CRP levels using the cutoff of $1 \mathrm{mg} / \mathrm{dL}$ used in previous studies. ${ }^{22,28}$ Although higher CRP levels do not necessarily indicate inflammation, Ridker and colleagues ${ }^{25,39}$ showed that 
TABLE 4. Postoperative outcomes after off-pump coronary artery bypass grafting

\begin{tabular}{|c|c|c|c|c|c|}
\hline Outcomes & Low CRP no RBC & Low CRP yes RBC & High CRP no RBC & High CRP yes RBC & $\boldsymbol{P}$ \\
\hline 30-d mortality & $3 / 331(0.9 \%)$ & $26 / 930(2.8 \%)$ & $1 / 62(1.6 \%)$ & $18 / 275(6.5 \%)$ & .001 \\
\hline 90-d mortality & $6 / 310(1.9 \%)$ & $44 / 867(5.1 \%)$ & $4 / 58(6.9 \%)$ & $43 / 253(17.0 \%)$ & $<.001$ \\
\hline $1-y$ mortality & $13 / 246(5.3 \%)$ & $76 / 725(10.5 \%)$ & $6 / 48(12.5 \%)$ & $62 / 205(30.2 \%)$ & $<.001$ \\
\hline 3-y mortality & $16 / 193(8.3 \%)$ & $80 / 534(15.0 \%)$ & $7 / 39(17.9 \%)$ & $51 / 152(33.6 \%)$ & $<.001$ \\
\hline
\end{tabular}

CRP levels of even 0.1 to 0.3 , thus not only greater than $0.3 \mathrm{mg} / \mathrm{dL}$, were associated with moderate and high risks of future cardiovascular events in healthy females.

\section{Study Limitations}

Our study had several limitations. First, the work was retrospective in nature. Although we adjusted for many perioperative clinical variables, some bias may be in play. Tran and colleagues ${ }^{40}$ indicated that the association between transfusion and mortality became insignificant after adjusting for postoperative complications such as renal failure, prolonged intubation, a need for reintubation, acute MI, or cardiac dysfunction. We adjusted for postoperative covariates, including acute kidney injury, any need for reintubation, and reoperation to control bleeding. However, adjustments for other postoperative morbidities, especially cardiac conditions, may be required. Second, we used only CRP as a marker of inflammation; the levels of other markers also may be clinically significant. However, CRP is an exquisitely sensitive marker, predicting postoperative outcomes. ${ }^{22,28}$ Third, we did not assess the dose-response effect of the inflammation/transfusion relationship. When defining transfusion triggers for patients undergoing cardiac surgery with preexisting inflammation, data on changes in patient outcome according to transfusion volume are required. Fourth, we do not answer the (important)

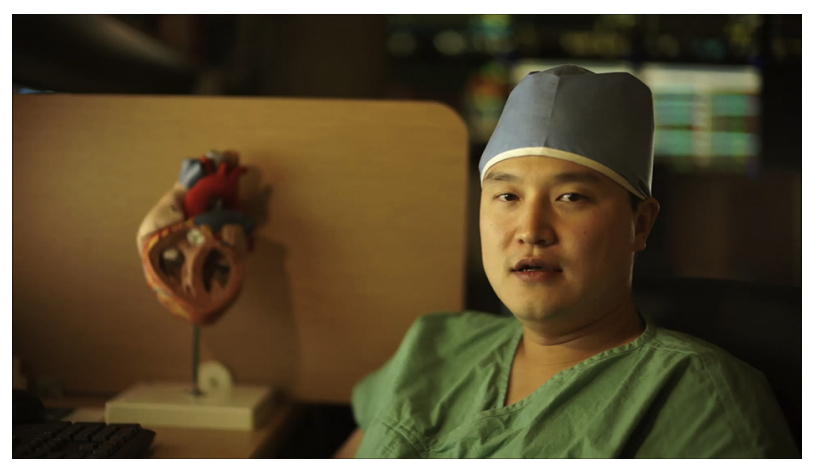

VIDEO 1. The effect of transfusion on mortality after OPCAB grafting can be affected by preoperative CRP level. Video available at: https:// www.jtcvs.org/article/S0022-5223(19)30292-2/fulltext. question: What is the cause of death of patients in the high CRP with transfusion group? Considering the key role played by inflammation in the development of atherosclerosis, ${ }^{18,19}$ we infer that such patients would more frequently experience recurrent vascular occlusive disease or graft failure.

\section{CONCLUSIONS}

We found that the effect of intraoperative RBC transfusion on mortality after OPCAB was influenced by preoperative CRP level. The risk of mortality after transfusion was significantly higher in patients with preexisting inflammation. These patients may need individualized transfusion triggers.

\section{Conflict of Interest Statement}

Authors have nothing to disclose with regard to commercial support.

\section{References}

1. Bennett-Guerrero E, Zhao Y, O'Brien SM, Ferguson TB Jr, Peterson ED, Gammie JS, et al. Variation in use of blood transfusion in coronary artery bypass graft surgery. JAMA. 2010;304:1568-75.

2. Paone G, Likosky DS, Brewer R, Theurer PF, Bell GF, Cogan CM, et al. Transfusion of 1 and 2 units of red blood cells is associated with increased morbidity and mortality. Ann Thorac Surg. 2014;97:87-93.

3. van Straten AH, Bekker MW, Soliman Hamad MA, van Zundert AA, Martens EJ, Schonberger JP, et al. Transfusion of red blood cells: the impact on short-term and long-term survival after coronary artery bypass grafting, a ten-year follow-up. Interact Cardiovasc Thorac Surg. 2010;10:37-42.

4. Kuduvalli M, Oo AY, Newall N, Grayson AD, Jackson M, Desmond MJ, et al. Effect of perioperative red blood cell transfusion on 30-day and 1-year mortality following coronary artery bypass surgery. Eur J Cardiothorac Surg. 2005;27: 592-8.

5. Murphy GJ, Reeves BC, Rogers CA, Rizvi SI, Culliford L, Angelini GD. Increased mortality, postoperative morbidity, and cost after red blood cell transfusion in patients having cardiac surgery. Circulation. 2007;116:2544-52.

6. Koch CG, Li L, Duncan AI, Mihaljevic T, Loop FD, Starr NJ, et al. Transfusion in coronary artery bypass grafting is associated with reduced long-term survival. Ann Thorac Surg. 2006;81:1650-7.

7. Surgenor SD, Kramer RS, Olmstead EM, Ross CS, Sellke FW, Likosky DS, et al. The association of perioperative red blood cell transfusions and decreased longterm survival after cardiac surgery. Anesth Analg. 2009;108:1741-6.

8. Engoren MC, Habib RH, Zacharias A, Schwann TA, Riordan CJ, Durham SJ. Effect of blood transfusion on long-term survival after cardiac operation. Ann Thorac Surg. 2002; 74:1180-6.

9. Koster A, Zittermann A, Borgermann J, Knabbe C, Diekmann J, Schirmer U, et al. Transfusion of 1 and 2 units of red blood cells does not increase mortality and organ failure in patients undergoing isolated coronary artery bypass grafting. Eur J Cardiothorac Surg. 2016;49:931-6. 
10. Warwick R, Mediratta N, Chalmers J, Pullan M, Shaw M, McShane J, et al. Is single-unit blood transfusion bad post-coronary artery bypass surgery? Interact Cardiovasc Thorac Surg. 2013;16:765-71.

11. Dardashti A, Ederoth P, Algotsson L, Bronden B, Luhrs C, Bjursten H. Blood transfusion after cardiac surgery: is it the patient or the transfusion that carries the risk? Acta Anaesthesiol Scand. 2011:55:952-61.

12. Weightman WM, Gibbs NM, Sheminant MR, Newman MA, Grey DE. Moderate exposure to allogeneic blood products is not associated with reduced long-term survival after surgery for coronary artery disease. Anesthesiology. 2009;111: 327-33.

13. Pathi VL, Morrison J, MacPhaden A, Martin W, McQuiston AM, Wheatley DJ. Alterations in renal microcirculation during cardiopulmonary bypass. Ann Thorac Surg. 1998;65:993-8.

14. Molitoris BA, Sandoval R, Sutton TA. Endothelial injury and dysfunction in ischemic acute renal failure. Crit Care Med. 2002;30:S235-40.

15. Onorati F, Rubino AS, Nucera S, Foti D, Sica V, Santini F, et al. Off-pump coronary artery bypass surgery versus standard linear or pulsatile cardiopulmonary bypass: endothelial activation and inflammatory response. Eur J Cardiothorac Surg. 2010;37:897-904.

16. Raja SG, Berg GA. Impact of off-pump coronary artery bypass surgery on systemic inflammation: current best available evidence. J Card Surg. 2007;22: 445-55.

17. Jongman RM, Zijlstra JG, Kok WF, van Harten AE, Mariani MA, Moser J, et al. Off-pump CABG surgery reduces systemic inflammation compared with onpump surgery but does not change systemic endothelial responses: a prospective randomized study. Shock. 2014;42:121-8.

18. Libby P. Inflammation in atherosclerosis. Nature. 2002;420:868-74.

19. Libby P, Theroux P. Pathophysiology of coronary artery disease. Circulation. 2005;111:3481-8.

20. Elkind MS. Inflammatory markers and stroke. Curr Cardiol Rep. 2009;11:12-20.

21. Lagrand WK, Visser CA, Hermens WT, Niessen HW, Verheugt FW, Wolbink GJ, et al. C-reactive protein as a cardiovascular risk factor: more than an epiphenomenon? Circulation. 1999;100:96-102.

22. Min JJ, Nam K, Kim TK, Kim HJ, Seo JH, Hwang HY, et al. Relationship between early postoperative C-reactive protein elevation and long-term postoperative major adverse cardiovascular and cerebral events in patients undergoing off-pump coronary artery bypass graft surgery: a retrospective study. $\mathrm{Br} J$ Anaesth. 2014;113:391-401.

23. Padayachee L, Rodseth RN, Biccard BM. A meta-analysis of the utility of $\mathrm{C}$-reactive protein in predicting early, intermediate-term and long term mortality and major adverse cardiac events in vascular surgical patients. Anaesthesia. 2009; 64:416-24.

24. Perry TE, Muehlschlegel JD, Liu KY, Fox AA, Collard CD, Body SC, et al. Preoperative C-reactive protein predicts long-term mortality and hospital length of stay after primary, nonemergent coronary artery bypass grafting. Anesthesiology. 2010;112:607-13.

25. Ridker PM, Rifai N, Rose L, Buring JE, Cook NR. Comparison of C-reactive protein and low-density lipoprotein cholesterol levels in the prediction of first cardiovascular events. N Engl J Med. 2002;347:1557-65.
26. Fransen E, Maessen J, Dentener M, Senden N, Buurman W. Impact of blood transfusions on inflammatory mediator release in patients undergoing cardiac surgery. Chest. 1999;116:1233-9.

27. Zallen G, Moore EE, Ciesla DJ, Brown M, Biffl WL, Silliman CC. Stored red blood cells selectively activate human neutrophils to release IL-8 and secretory PLA2. Shock. 2000;13:29-33.

28. Kangasniemi OP, Biancari F, Luukkonen J, Vuorisalo S, Satta J, Pokela R, et al. Preoperative C-reactive protein is predictive of long-term outcome after coronary artery bypass surgery. Eur J Cardiothorac Surg. 2006;29: 983-5.

29. Delaney M, Wendel S, Bercovitz RS, Cid J, Cohn C, Dunbar NM, et al. Transfusion reactions: prevention, diagnosis, and treatment. Lancet. 2016;388: 2825-36.

30. Rohde JM, Dimcheff DE, Blumberg N, Saint S, Langa KM, Kuhn L, et al. Health care-associated infection after red blood cell transfusion: a systematic review and meta-analysis. JAMA. 2014;311:1317-26.

31. Murphy GJ, Pike K, Rogers CA, Wordsworth S, Stokes EA, Angelini GD, et al Liberal or restrictive transfusion after cardiac surgery. N Engl J Med. 2015;372: 997-1008.

32. Mazer CD, Whitlock RP, Fergusson DA, Hall J, Belley-Cote E, Connolly K, et al. Restrictive or liberal red-cell transfusion for cardiac surgery. N Engl J Med. 2017; 377:2133-44.

33. Carson JL, Terrin ML, Noveck H, Sanders DW, Chaitman BR, Rhoads GG, et al. Liberal or restrictive transfusion in high-risk patients after hip surgery. $N$ Engl $J$ Med. 2011;365:2453-62.

34. Carson JL, Brooks MM, Abbott JD, Chaitman B, Kelsey SF, Triulzi DJ, et al. Liberal versus restrictive transfusion thresholds for patients with symptomatic coronary artery disease. Am Heart J. 2013;165:964-971 e1.

35. Lambert N, Nelson JL. Microchimerism in autoimmune disease: more question than answers? Autoimmun Rev. 2003;2:133-9.

36. Blajchman MA. Immunomodulation and blood transfusion. Am J Ther. 2002;9: 389-95.

37. Utter GH, Nathens AB, Lee TH, Reed WF, Owings JT, Nester TA, et al. Leukoreduction of blood transfusions does not diminish transfusion-associated microchimerism in trauma patients. Transfusion. 2006;46:1863-9.

38. Engoren M, Schwann TA, Habib RH, Neill SN, Vance JL, Likosky DS. The independent effects of anemia and transfusion on mortality after coronary artery bypass. Ann Thorac Surg. 2014;97:514-20.

39. Ridker PM, Buring JE, Cook NR, Rifai N. C-reactive protein, the metabolic syndrome, and risk of incident cardiovascular events: an 8-year follow-up of 14719 initially healthy American women. Circulation. 2003;107:391-7.

40. Tran L, Greiff G, Pleym H, Wahba A, Stenseth R, Videm V. Transfusion of red blood cells in coronary surgery: is there an effect on long-term mortality when adjusting for risk factors and postoperative complications? Eur J Cardiothorac Surg. 2018;53:1068-74.

Key Words: coronary artery bypass grafting, C-reactive protein, inflammation, mortality, transfusion 